\title{
Spam Detection in Twitter using Machine Learning Algorithms
}

\author{
S. Jeyapriyanga, B. Mahalakshmi, Anuradha C
}

\begin{abstract}
Twitter is being one of the most generally utilized interpersonal organizations on the planet which has been a key objective for interlopers. In this work, Identifying spammers in twitter System is to be proposed which isolate the spammers tweets among specialists tweets by distinguishing and recognizing twitter messages. Here the emphasis depends on the tweet level spammer recognition. This work is a methodology for recognizing spammer tweets among specialists tweets utilizing three classifiers, for example, Best First Decision Tree, $K$ Nearest Neighbor. This thusly prompts better tweet characterization. The thing to be considered is the preparation information is created naturally as master tweets and spammers tweets. It is finished by investigating the tweets and extricating watchwords. The HITS calculation is utilized to rank the spammers. Three classifiers here are utilized to characterize the tweets and casting a ballot strategy is utilized to mark the most extreme estimations of the tweets which has been arranged by the classifiers.
\end{abstract}

Keywords: Twitter, spam tweets, ham tweets, detector, ensemble, classifier, Blacklist, Machine learning.

\section{INTRODUCTION}

Microblogging, similar to Twitter and Sina Weibo, has turned into a broadly well known stage for data scattering and partaking in different situations, for example, showcasing, reporting or advertising. With the developing accessibility of microblog-ging, social spamming has turned out to be uncontrolled. Many phony air conditioning tallies, known as social spammers, are utilized to unreasonably overwhelm ordinary clients. Social spammers can be facilitated to dispatch different assaults, for example, befriending exploited people and afterward snatching their own data directing spam battles which lead to phishing, malware, and tricks, and leading political astroturf fruitful social spammer identification in microblogging presents its centrality to improve the nature of client experience, and to decidedly affect the general estimation of the social frameworks going forward.[4]. The achievement of Twitter (and different OSNs) as a stage for huge scale correspondence and the extension of endeavors to dig their information for new and novel applications identified with general wellbeing, financial improvement, logical dispersal and so forth., basically relies on the realness of their client database. A sub-area of OSN clients on most stages are not true. These "phony" clients (or Sybils/Socialbots) are produced deliberately, and regularly

Revised Manuscript Received on August 22, 2019.

S.Jeyapriyanga, Department of Computer science and Engineering, Bharath Institute of Higher Education and Research, Chennai, Tamilnadu, India. Email: priyankashanmugam16@gmail.com

B.Mahalakshmi, Department of Computer science and Engineering, Bharath Institute of Higher Education and Research, Chennai, Tamilnadu, India. Email: mahalakshmibalaji304@gmail.com

Anuradha C, Department of Computer science and Engineering, Bharath Institute of Higher Education and Research, Chennai, Tamilnadu, India. Email: anuradha.ak23@gmail.com consequently/semi-naturally, by digital sharks (or digital hoodlums). The phony clients (or their administrators) may

send solicitations to 'pursue' or 'companion' other OSN clients and increase fame when these solicitations are acknowledged. The nearness of phony adherents can: inclination an individual or association's notoriety dependent on devotee number check adjust the qualities of the group of spectators ; or make an authenticity issue for people/associations[14],[16],[18]. Now and again a phony profile is made to basically copy a client's online nearness, and these "character clone assaults" are conceived to coordinate online extortion.

There are two fundamental difficulties of spammer recognition on Twitter.1. The principal challenge is the means by which to process a huge measure of Twitter information. Today[9], Twitter administrations handle more than 2.8 billion demands and store 4.5petabytes of time arrangement information consistently (Twitter, 2016). We need a methodology that can most likely scale up to deal with a gigantic volume of information with restricted calculation capacity.2. Quick difference in spamming examples is the subsequent test. The social spammer discovery generally appears to be an unending game among spammers and hostile to spam frameworks. Spammers persistently change their spamming methodology to trick the counter spam frameworks.

A methodology that can almost certainly adjust to the complex, and quick changing of information is required[8],[10],[12].

So we centeraround Twitter and we propose a novel, compelling way to deal with recognize and channel undesirable tweets. Past stud-ies depend on recorded highlights of tweets that are regularly inaccessible on Twitter after a brief timeframe, subsequently not reasonable for constant use. Our methodology uses an advanced arrangement of promptly profit capable highlights, Independent of authentic literary highlights on Twit-ter. The utilized highlights are sorted as identified with the Twitter account, the client or bloggers alluding to the tweet posted by specialists[13],[15],[17]. 


\section{SYSTEM ARCHITECTURE}

\section{A. Data Processing}

Pre-taking care of is considered as a basic advancement in substance mining. There are three stages in Pre-dealing with errand for tweet demand, which are tokenization, stop word discharge and stemming. Starting development is tokenization process, in which all photos, supplements and numbers will be exhausted. The rest of the strings will be detached into tokens. Second step is stop word clearing[19],[21],[23]. A broad package of the as much of the time as possible utilized words in English are minor in Information Retrieval (IR) and substance mining process. These words are called 'Stop words', which are language-express utilitarian words and unending words that pass on no data (i.e., pronouns, social words, conjunctions). In this development, the crucial words, which are the most incessant words that exist in a document are discharged. In English language, there are around 400-500 Stop words and this quick overview depends upon word rehash. This framework will see which words those match with the stop word records by looking two[7],[9],[11]. Expelling these words will additional areas for dealing with record substance and reduce time taken during the looking through framework. Third step is Stemming, which means finding the starting phase of the words and clearing prefixes and postfixes. By utilizing Stemming, sorts of a word like modifiers, things and movement words are changed over to homological like word. For example, both 'getting' and 'caught' are changed over to an equivalent

\section{B. Selection}

In the selection phase the preprocessed tweets are processed using rake algorithm to extract the keywords. The domain based keywords are extracted.

To extract the keywords, the dictionary is created which contain the domain based keywords. Using this the rake algorithm the keywords are extracted from the given tweets.

\section{Algorithm}

RAKE short for Rapid Automatic Keyword Extraction calculation, is a space free watchword extraction calculation which attempts to decide key expressions in an assortment of content by examining the recurrence of word appearance and its co-event with different words in the content[26],[28],[30].

\section{Ranking}

Followed to selection process the ranking process involves the process of user attribute matrix is construction based on the keywords and the tweet characteristics. From the constructed matrix the hub and authority scores are calculated for ranking the bloggers. Hyperlink induced Topic Search (HITS) algorithm is used to rank the top unsolicitated users. Using hyperlink induced topic search algorithm ranking is followed.

Thus the solicited bloggers are ranked which is used as training set for classification. Figure 3.4 represents the ranking process.

\section{Algorithm}

- HITS is applied on a sub graph or lattice after an inquiry is done on the total framework[20],[22],[24].

- Uses centers and specialists to characterize a recursive connection between framework sections. A specialist is a page that numerous center points connect to. A center point is a page that connects to numerous specialists.

\section{RESEARCH DIRECTIONS}

\section{A. Classifier subsystem}

\section{Decision Tree}

Given a lot of preparing occasions E, its strategy of characteristics A, the fixed number of enhancements and the fixed immaterial number of occasions at a terminal focus point $\mathrm{M}$, the check can be detached into two phases. In the boss create, the check begins at the root focus point $\mathrm{RN}$ and finds the best isolating property $\mathrm{Ab}$ in $\mathrm{An}$ as indicated by the decrease of contamination. $\mathrm{E}$ and $\mathrm{Ab}$ are kept in RN. By at that point, $\mathrm{RN}$ is consolidated into the vacant focus point list NL. In the following stage, the significant focus FN in NL, and its seeing best isolating quality $\mathrm{Ab}$ and the models meeting up at the inside $\mathrm{E}$ are recovered first. If the diminishing of degradation of $\mathrm{FN}$ is 0 or Nis gone to, all centers in the once-over NL are made into terminal centers and the route toward building up the best-first decision tree is finished. Something different, if the split of F Non Ab would incite a successor center point with not as much as $\mathrm{M}$ events, FN should not be part and it is removed from N L. By then, the count executes this stage again with the new center point list $\mathrm{N}$ L. If the split doesn't prompts this circumstance, FNis split into two successor center points SN1 and SN2(i.e. branches) in light of its best separating quality $\mathrm{Ab}$, and its readiness events $\mathrm{E}$ are detached into two relating subsets $\mathrm{E} 1$ and $\mathrm{E} 2$, one for each branch. By then, the best reduction of tainting for SN1 and SN2, and the looking at best separating qualities Ab1 and $\mathrm{Ab} 2$, are resolved. In the consequent stage SN1 with $\mathrm{Ab} 1$ and E1, and SN2 with $\mathrm{Ab} 2$ and E2 are included into $\mathrm{N} \mathrm{L}$ according to the diminishing of degradation (for instance $\mathrm{N}$ Lis kept up in organized control). The amount of improvements of the tree is expanded.

Expand Tree (N L,N,M); end by one. Next, F Nis evacuated from $\mathrm{N}$ L. At long last, this stage is rehashed with the newnode list $\mathrm{N} \mathrm{L}$. When building choice trees, for a numeric quality, it is a smart thought to sort the preparing occurrences by the estimations of the trait at the root hub and after that ever relative hub can utilize the sort request from its parent hub. The reason is that, for an enormous dataset, in the event that we sort occasions at every hub the sorting time is very expensive. To accomplish the objective, the main thing that should be done is to keep the arranged files of the parent hub, and the successor hubs would then be able to get the indexes from the parent hub.

The hour of the determination is straight in the number of instances while the hour of

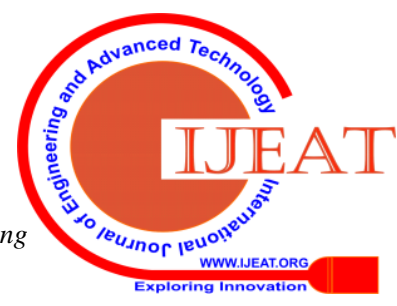


re-arranging cases is log-direct. For an ostensible attribute, as referenced previously, if comprehensive pursuit is utilized, the calculation time is exponential in the quantity of estimations of the characteristic. In the event that heuristic search is utilized, the computation time develops directly in the quantity of the quality qualities.

\section{B. K nearest neighbor}

KNN is among the simplest of all machine learning algorithms. KNN a non-parametric lazy algorithm delay the process of modeling training data until they need it to classify new data. A case is classified by a majority vote of its neighbors, with the case being assigned to the class most common amongst its $\mathrm{K}$ nearest neighbors measured by a distance function. If $K=1$, then the case is simply assigned to the class of its nearest neighbor. A Euclidean Distance measure is used to calculate how close each member of the training set is to the test class that is being examined [2]. say, $\mathrm{X}=(\mathrm{x} 1, \mathrm{x} 2, \ldots \ldots, \mathrm{xn})$ and $\mathrm{Y}=(\mathrm{y} 1, \mathrm{y} 2, \ldots \ldots . . \mathrm{yn})$, is Detection of spam has become a challenger task for researchers as well as for Twitter itself. In this paper accuracy of KNN algorithm is evaluated in classifying tweets as spam or non-spam. Machine learning algorithms cannot be directly applied to tweets. Several steps need to be followed before applying any machine learning algorithms[2],[4],[6].

K-nearest neighbor (Knn) algorithm pseudocode:

Let $\left(\mathrm{X}_{\mathrm{i}}, \mathrm{C}_{\mathrm{i}}\right)$ where $\mathrm{i}=1,2 \ldots \ldots, \mathrm{n}$ be data points. $\mathrm{X}_{\mathrm{i}}$ denotes feature values $\& \mathrm{C}_{\mathrm{i}}$ denotes labels for $\mathrm{X}_{\mathrm{i}}$ for each $\mathrm{i}$.Assuming the number of classes as ' $c$ ' ${ }_{\mathrm{Ci}} \in\{1,2,3, \ldots \ldots, \mathrm{c}\}$ for all values of $i$.

Let $\mathrm{x}$ be a point for which label is not known, and we would like to find the label class using k-nearest neighbor algorithms.

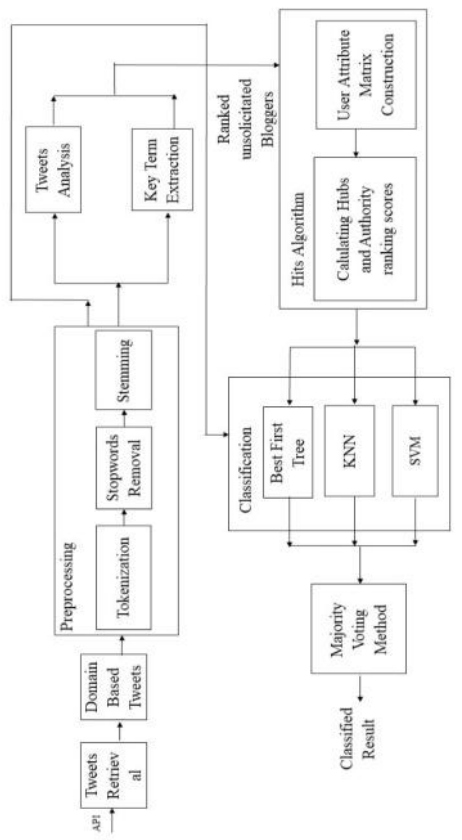

Figure1-System architecture

\section{EXPERIMENTS AND RESULTS}

\section{A. Dataset}

To assess the adequacy of our spammer identification calculation, we gather genuine Twitter information from Twitter site. We gathered new information from Twitter in light of the fact that all the public available Twitter datasets available are not space based.

Thusly it is important to have new information for assessment. The information gathering calculation began with an arbitrary Twitter account from which we further downloaded a rundown of specialists. we at that point arbitrarily chosen bloggers from that twitter. We rehashed the procedure until we acquired sufficient number of records. We gathered information over the long time utilizing the python API given by Twitter to the information accumulation and put away them in a framework. For every client we recorded the fundamental profile and the id and their tweets. The dataset includes the way toward creating preparing set. It has been utilized independently for testing and preparing. Among 100 percent of these tweets 20 percent tweets utilized for preparing and 80 percent for testing. The assessment measurements considered to assess the exhibition of the application are Precision, Recall and F1 Score. These measurements help to perform relative execution investigation of different indicators and classifiers utilized in the proposed framework.

Genuine Positives (TP) - These are the effectively anticipated positive qualities, which implies that the estimation of real class is yes and the estimation of anticipated class is additionally yes.

Genuine Negatives (TN) - These are the accurately anticipated negative qualities which implies that the estimation of real class is no and estimation of anticipated class is likewise no. False positives and false negatives, these qualities happen when your genuine class repudiates with the anticipated class.

False Positives (FP) - When real class is no and anticipated class is yes.

False Negatives (FN) - When real class is yes yet anticipated class in no.

Precision - Accuracy is the most instinctive exhibition measure and it is basically a proportion of accurately anticipated perception to the all out perceptions. On the off chance that there is high precision, at that point the model is viewed as the best and give better anticipated outcome. This measure can be utilized just when there is symmetric datasets where estimations of false positive and false negatives are practically same. The proposed model has accomplished a precision of $100 \%$ for the dataset under thought.

\section{Exactness $=\mathrm{TP}+\mathrm{TN} / \mathrm{TP}+\mathrm{FP}+\mathrm{FN}+\mathrm{TN}$}

Accuracy - Precision is the proportion of accurately 
anticipated positive perceptions to the complete anticipated positive perceptions. High exactness identifies with the low false positive rate. Here this spam discovery framework have about 1.00 exactness which is quite great.

Accuracy estimates the level of tweets hailed as spammer tweets that were effectively grouped

Accuracy $=\mathrm{TP} / \mathrm{TP}+\mathrm{FP}$

Review - Recall is the proportion of effectively anticipated positive perceptions to every single positive perception in real class. The proposed framework has a review of 1.00 which is useful for this model.

Review estimates the level of genuine spammer tweets that were effectively characterized.

\section{Review $=\mathrm{TP} / \mathrm{TP}+\mathrm{FN}$}

F1 score - F1 Score is the weighted typical score of Precision and Recall. In this way, this score thinks about both false positives and false negatives. F1 is commonly more important than accuracy, especially in case you have an uneven class flow. Accuracy works best if false positives and false negatives have similar cost. In case the cost of false positives and false negatives are by and large unique, it's more astute to look at both Precision and Recall. For our circumstance, F1 score is 1.00 .

F1 Score $=2 *($ Recall $*$ Precision $) /($ Recall + Precision $)$

\begin{tabular}{|c|c|}
\hline $\begin{array}{l}\text { Evaluation } \\
\text { Metric }\end{array}$ & Details of the Metric \\
\hline $\begin{array}{l}\mathrm{TP} \\
\text { Positive) }\end{array}$ & $\begin{array}{l}\text { Spammer tweets that correctly } \\
\text { predicted as Spammer tweets. }\end{array}$ \\
\hline $\begin{array}{l}\text { TN } \\
\text { Negative) }\end{array}$ & $\begin{array}{l}\text { Expert tweets that correctly } \\
\text { predicted as expert tweets (Non } \\
\text { Spammers) }\end{array}$ \\
\hline $\begin{array}{ll}\text { FP } & \text { (False } \\
\text { Positive) } & \end{array}$ & $\begin{array}{l}\text { Expert tweets that misclassified as } \\
\text { Spammer tweets. }\end{array}$ \\
\hline $\begin{array}{ll}\text { FN } & \text { (False } \\
\text { Negative) } & \end{array}$ & $\begin{array}{l}\text { Spammer tweetsthat misclassified as } \\
\text { experts tweets. (Non Spam) }\end{array}$ \\
\hline
\end{tabular}

\begin{tabular}{|l|l|l|}
\hline No & CLASSIFIERS & $\begin{array}{l}\text { Classification of } \\
\text { tweets }\end{array}$ \\
\hline 1. & $\begin{array}{l}\text { BEST } \\
\text { DECISION TREE }\end{array}$ & $\mathbf{9 0 \%}$ \\
\hline 2. & $\begin{array}{l}\text { K N NEAREST } \\
\text { NEIGHBOR }\end{array}$ & $\mathbf{8 0 \%}$ \\
\hline
\end{tabular}

\section{B. Accuracy Graph for the Classifiers}

Support Vector Machines and Best First Decision tree gives good accuracy as 1.00 than K Nearest Neighbor givers 0.96.K Nearest Neighbor more or less equal to Support Vector Machines and Best First Search tree but not equal to.

\begin{tabular}{l|l} 
Classifiers & Accuracy
\end{tabular}

\begin{tabular}{|l|l|}
\hline K Nearest Neighbor & 0.96 \\
\hline Best First Decision tree & 1.00 \\
\hline
\end{tabular}

\section{CONCLUSION}

In the ongoing innovation world, Twitter is one of the significant online networking Application, which is utilized to join individuals crosswise over districts and give a typical stage to impart their own insights, musings, emotions and substantially more for a typical just as more noteworthy reason. In such a noteworthy mode of correspondence, it is significant that spam messages or remarks don't impede the clients and make them go amiss from the more prominent reason, as this diminishes the essential expectation of the application and decreases the proficiency of the foundation. In this paper, the spammer and specialists tweets are named utilizing the classifiers in particular - Best first choice tree, bolster vector machines and $\mathrm{K}$ closest neighbor. The classifiers recognize the tweets successfully. As the examination and results segment has uncovered, taking a gander at all the parameters all things considered, it is discovered that help vector machines and Best First Decsion tree is the best classifier of this sort of activity and gives more exactness than $\mathrm{K}$ closest neighbor. F-measure, which speaks to the exactness, is the most astounding for help vector machines and Best First Decision tree and it likewise has the most astounding accuracy score. It will help in characterizing the spammer tweets among the master tweets separately. Then again, it is likewise observed that outfit of classifiers system helps in learning ability of the classifiers[1],[3],[5]. The time taken to manufacture the model for the best classifier found for this examination, is additionally less. In any case, as officially settled classifiers utilized. Thus the outcomes are progressively successful and simple to prepare the classifiers too. The significant thing in this work is creating the preparation information for the classifier dependent on positioning framework utilizing hits calculation. In this way the classifiers did well by positioned preparing information utilizing HITS calculation. The outcomes prompt great score.

\section{REFERENCES}

1. Gowri Sankaran, B., Karthik, B. \& Vijayaragavan, S.P. 2019, "Weight ward change region plummeting change for square based image huffman coding", International Journal of Innovative Technology and Exploring Engineering, vol. 8, no. 10, pp. 4313-4316.

2. Gowri Sankaran, B., Karthik, B. \& Vijayaragavan, S.P. 2019, "Image compression utilizing wavelet transform", International Journal of Innovative Technology and Exploring Engineering, vol. 8, no. 10, pp. 4305-4308.

3. Kandavel, N. \& Kumaravel, A. 2019, "Offloading computation for efficient energy in mobile cloud computing", International Journal of Innovative Technology and Exploring Engineering, vol. 8, no. 10, pp. 4317-4320.

4. Vinoth, V.V. \& Kanniga, E. 2019, "Reversible data hiding in encrypting images-an system", International Journal of Engineering and Advanced Technology, vol. 8, no. 6, pp. 3051-3053.

5. Selvapriya, B. \& Raghu, B. 2019, "Pseudocoloring of medical images: A research", International Journal of Engineering and Advanced Technology, vol. 8, no. 6, pp. 3712-3716.

6. Senthil Kumar, K. \& Muthukumaravel, A. 2019, "Bi-objective constraint and hybrid optimizer for the test case prioritization", International Journal of Engineering and Advanced 
Technology, vol. 8, no. 6, pp. 3436-3448.

7. Kavitha, G., Priya, N., Anuradha, C. \& Pothumani, S. 2019, "Read-write, peer-to-peer algorithms for the location-identity split", International Journal of Innovative Technology and Exploring Engineering, vol. 8, no. 9 Special Issue 3, pp. 445-447.

8. Kaliyamurthie, K.P., Michael, G., Anuratha, C. \& Sundaraj, B. 2019 "Certain improvements in alzheimer disease classification using novel fuzzy c means clustering for image segmentation", International Journal of Innovative Technology and Exploring Engineering, vol. 8 , no. 9 Special Issue 3, pp. 599-604.

9. Kaliyamurthie, K.P., Sundarraj, B., Geo, A.V.A. \& Michael, G. 2019 , "RIB: Analysis of I/O automata", International Journal of Innovative Technology and Exploring Engineering, vol. 8, no. 9 Special Issue 3 , pp. 1019-1022.

10. Velvizhi, R., Rajabhushanam, C. \& Vidhya, S.R.S. 2019, "Opinion mining for travel route recommendation using Social Media Networks (Twitter)", International Journal of Innovative Technology and Exploring Engineering, vol. 8, no. 9 Special Issue 3, pp. 508-512.

11. Kavitha, R., Sangeetha, S. \& Varghese, A.G. 2019, "Human activity patterns in big data for healthcare applications", International Journa of Innovative Technology and Exploring Engineering, vol. 8, no. 9 Special Issue 3, pp. 1101-1103.

12. Pothumani, S., Anandam, A.K., Sharma, N. \& Franklin, S. 2019 "Extended VEOT framework - Implemented in a smart boutique", International Journal of Innovative Technology and Exploring Engineering, vol. 8, no. 9 Special Issue 3, pp. 762-767.

13. Kaliyamurthie, K.P., Michael, G., Krishnan, R.M.V. \& Sundarraj, B. 2019, "Pseudorandom techniques for the internet", International Journal of Innovative Technology and Exploring Engineering, vol. 8, no. 9 Special Issue 3, pp. 915-918.

14. Aravindasamy, R., Jeffrin Rajan, M., Rama, A. \& Kavitha, P. 2019, "Deep learning provisions in the matlab: Focus on CNN facility", International Journal of Innovative Technology and Exploring Engineering, vol. 8, no. 9 Special Issue 3, pp. 990-994.

15. Theivasigamani, S., Linda, M. \& Amudha, S. 2019, "Object sensing and its identification \& motion sensing", International Journal of Innovative Technology and Exploring Engineering, vol. 8, no. 9 Special Issue 3, pp. 545-549.

16. Mary Linda, I., Vimala, D. \& Shanmuga Priya, K. 2019, "A methodology for the emulation of IPv4", International Journal of Innovative Technology and Exploring Engineering, vol. 8, no. 9 Special Issue 3, pp. 848-852.

17. Velvizhi, R., Priya, D.J., Vimala, D. \& Linda, I.M. 2019, "Increased routing algorithm for mobile adhoc networks", International Journal of Innovative Technology and Exploring Engineering, vol. 8, no. 9 Special Issue 3, pp. 1606-1608

18. Sangeetha, S., Anuradha, C. \& Priya, N. 2019, "DNS in real world", International Journal of Innovative Technology and Exploring Engineering, vol. 8, no. 9 Special Issue 3, pp. 937-940.

19. Geetha, C., Vimala, D. \& Priya, K.S. 2019, "Constructing multi-processors and spreadsheets with SKIVE", International Journal of Innovative Technology and Exploring Engineering, vol. 8, no. 9 Special Issue 3, pp. 516-519.

20. Yugendhar, K., Sugumar, V. \& Kavitha, P. 2019, "A novel method of univac using fuzzy logic", International Journal of Innovative Technology and Exploring Engineering, vol. 8, no. 9 Special Issue 3 , pp. 435-437.

21. Kaliyamurthie, K.P., Michael, G., Elankavi, R. \& Jijo, S.A. 2019 "Implementing aggregate-key for sharing data in cloud environment using cryptographic encryption", International Journal of Innovative Technology and Exploring Engineering, vol. 8, no. 9 Special Issue 3, pp. 957-959.

22. Jeffrin Rajan, M., Aravindasamy, R., Kavitha, P. \& Rama, A. 2019, "A novel method of object orientation variation in $\mathrm{C}++$ and java", International Journal of Innovative Technology and Exploring Engineering, vol. 8, no. 9 Special Issue 3, pp. 708-710.

23. Nayak, R., Dinesh, S. \& Thirunavukkarasu, S. 2019, "A novel method improvement of rapid miner for the data mining applications", International Journal of Innovative Technology and Exploring Engineering, vol. 8, no. 9 Special Issue 3, pp. 457-460.

24. Sivaraman, K., Krishnan, R.M.V., Sundarraj, B. \& Sri Gowthem, S. 2019, "Network failure detection and diagnosis by analyzing syslog and SNS data: Applying big data analysis to network operations", International Journal of Innovative Technology and Exploring Engineering, vol. 8, no. 9 Special Issue 3, pp. 883-887.

25. Vimala, D., Linda, I.M. \& Priya, K.S. 2019, "Decoupling online algorithms from erasure coding in DNS", International Journal of
Innovative Technology and Exploring Engineering, vol. 8, no. 9 Special Issue 3, pp. 950-953

26. Rama, A., Kumaravel, A. \& Nalini, C. 2019, "Preprocessing medica images for classification using deep learning techniques", Internationa Journal of Innovative Technology and Exploring Engineering, vol. 8 , no. 9 Special Issue 3, pp. 711-716.

27. Sangeetha, S., Srividhya, S.R., Anita Davamani, K. \& Amudha, S. 2019, "A procedure for avoid overrun error in universal synchronous asynchronous receiver transmitter (usart) by utilizing dummy join and interrupt latency method", International Journal of Innovative Technology and Exploring Engineering, vol. 8, no. 9 Special Issue 3, pp. 657-660.

28. Aravindasamy, R., Jeyapriya, D., Sundarajan, B. \& Sangeetha, S. 2019, "Data duplication in cloud for optimal performance and security", International Journal of Innovative Technology and Exploring Engineering, vol. 8, no. 9 Special Issue 3, pp. 1156-1158.

29. Aravindasamy, R., Jeffrin Rajan, M., Sugumar, V. \& Kavitha, P. 2019 "A novel method on developing superblocks and the transistor using apodryal", International Journal of Innovative Technology and Exploring Engineering, vol. 8, no. 9 Special Issue 3, pp. 982-985.

30. Sasikumar, C.S. \& Kumaravel, A. 2019, "E-learning attributes selection through rough set theory and data mining", International Journal of Innovative Technology and Exploring Engineering, vol. 8 , no. 10 , pp. $3920-3924$

\section{AUTHORS PROFILE}

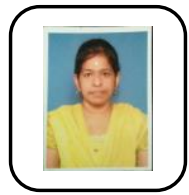

S.Jeyapriyanga Assistant Professor, Department of Computer science and Engineering, Bharath Institute of Higher Education and Research, Chennai, India

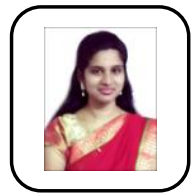

B.Mahalakshmi Assistant Professor, Department of Computer science and Engineering, Bharath Institute of Higher Education and Research, Chennai, India

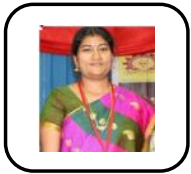

Anuradha C Assistant Professor, Department of Computer science and Engineering, Bharath Institute of Higher Education and Research, Chennai, India 